\title{
Hypokalaemic paralysis revealing Sjögren syndrome in an elderly man
}

\author{
M A Al-Jubouri, S Jones, R Macmillan, C Harris, R D Griffiths
}

\begin{abstract}
A 73 year old white man presented with life threatening hypokalaemic paralysis requiring admission to an intensive care unit. Biochemical investigations showed severe hypokalaemia with hyperchloraemic metabolic acidosis, a spot urine $\mathrm{pH}$ of 6.5 , and a positive urinary anion gap, establishing the diagnosis of distal renal tubular acidosis. Autoimmune tests revealed Sjögren syndrome as the underlying cause of the distal renal tubular acidosis. Full recovery followed potassium and alkali replacement. This dramatic presentation of Sjögren syndrome has not previously been reported in an elderly man.

(F Clin Pathol 1999;52:157-158)
\end{abstract}

Keywords: hypokalaemic paralysis; renal tubular acidosis; Sjögren syndrome

Sjögren syndrome, an autoimmune exocrinopathy, can occur as an entity on its own (primary Sjögren syndrome) or in association with other autoimmune rheumatic disorders, most often rheumatoid arthritis, systemic lupus erythematosus, and scleroderma (secondary Sjögren syndrome). Overt or latent renal tubular acidosis, caused by autoimmune tubulointerstitial nephropathy, is a common extraglandular manifestation occurring in $33 \%$ of Sjögren syndrome patients. ${ }^{1}$ Hypokalaemic paralysis is a well known, albeit rare, complication of severe distal renal tubular acidosis from any cause. ${ }^{23}$ Cases of Sjögren syndrome manifesting for the first time as hypokalaemic paralysis caused by severe distal renal tubular acidosis have been reported from various parts of the world. ${ }^{4-6}$ As far as we are aware, this presentation of Sjögren syndrome has not been reported from the United Kingdom. We therefore report such a case to increase awareness of this dramatic presentation of the syndrome.

Department of Chemical Pathology, Whiston Hospital, Prescot, Merseyside L35 5DR, UK

M A Al-Jubouri

Intensive Care Unit, Whiston Hospital

S Jones

R Macmillan

C Harris

R D Griffiths

Correspondence to Dr Al-Jubouri.

Accepted for publication 27 October 1998 day and drank 14 units of alcohol a week.

On examination, he was conscious, oriented, and did not smell of alcohol, though he looked very frail and dehydrated. Recumbent blood pressure was $165 / 70 \mathrm{~mm} \mathrm{Hg}$, pulse rate was 98 beats/min and regular, jugular venous pressure was not raised, lung fields were clear, and heart sounds were normal. Abdominal examination showed no abnormality.

On CNS examination, the cranial nerves were intact. There was proximal muscle weakness and wasting, more prominent in the legs than in the arms, with no evident muscle tenderness. Reflexes were normal apart from bilateral diminished ankle jerks. A straight leg raising test showed no abnormality, and there were no sensory deficits. An ECG showed sinus rhythm with obvious flattening of the $T$ waves in all leads. A chest radiograph showed left basal shadowing only.

Various blood tests were performed and the results were as follows (normal range in parentheses): potassium $1.6 \mathrm{mmol} /$ litre (3.5-5.2), sodium $138 \mathrm{mmol} /$ litre (135-145), urea 8.3 $\mathrm{mmol} /$ litre (2.5-7.5), creatinine $253 \mu \mathrm{mol} /$ litre (50-120), glucose $6.1 \mathrm{mmol} /$ litre (fasting 3.55.5), calcium $2.53 \mathrm{mmol} /$ litre (2.20-2.63), phosphate $0.42 \mathrm{mmol} /$ litre $(0.8-1.4)$, and magnesium $1.02 \mathrm{mmol} /$ litre (0.7-0.95). Thyroid function tests and muscle enzymes were normal. Haematological studies showed a haemoglobin concentration of $9.8 \mathrm{~g} / \mathrm{dl}\left(13.0_{-}\right.$ 17.5), a white cell count of $14.9 \times 10^{9} /$ litre (4.0-11.0), a platelet count of $172 \times 10^{9} /$ litre (150-400), plasma viscosity $1.88(1.50-1.72)$ centopoise, prothrombin time 12.9 seconds (12-16), and international normalised ratio (INR) 0.9 (0.9-1.3).

In response to the profound hypokalaemia and hypophosphataemia with moderate renal impairment, a saline infusion with potassium and phosphate supplements was started. Further investigation of the original blood sample showed a serum bicarbonate of $8.0 \mathrm{mmol} /$ litre (22-30) and chloride of $119 \mathrm{mmol} /$ litre (95-105). The patient thus had a hypokalaemic hyperchloraemic metabolic acidosis and in the absence of significant diarrhoea a diagnosis of renal tubular acidosis was likely. A spot urine sample while the patient was acidotic (serum bicarbonate $8.0 \mathrm{mmol} /$ litre) and hypokalaemic (serum potassium $1.6 \mathrm{mmol} /$ litre) showed a $\mathrm{pH}$ of 6.5 and a positive anion gap (urinary sodium $5.0 \mathrm{mmol} /$ litre, potassium $34 \mathrm{mmol} /$ litre, and chloride $<5 \mathrm{mmol} /$ litre), confirming the diagnosis of renal tubular acidosis type 1 (distal renal tubular acidosis).

While receiving fluid therapy with potassium and phosphate supplements, the patient developed increasing shortness of breath from respiratory muscle weakness. Repeat biochemical analyses showed a serum potassium of 1.7 
$\mathrm{mmol} /$ litre, sodium $144 \mathrm{mmol} /$ litre, urea 10.1 $\mathrm{mmol} /$ litre, and creatinine $268 \mu \mathrm{mol} /$ litre. On arterial blood gas analysis, the $\mathrm{pH}$ was 7.03 (7.35-7.45), $\mathrm{PCO}_{2} 6.1 \mathrm{kPa}(4.5-6.1), \mathrm{Po}_{2} 12.7$ $\mathrm{kPa}(12.0-15.0)$, bicarbonate $12.0 \mathrm{mmol} /$ litre (22.0-26.0), and oxygen saturation $92.6 \%$.

He was transferred to a high dependency unit 36 hours after hospital admission, where he showed further deterioration in his respiratory muscle movement and was therefore intubated and fully ventilated. Further clinical and radiological assessment showed that he had developed aspiration pneumonia for which he spent the next 13 days in the intensive care unit (ICU). While in ICU his metabolic derangement was managed with potassium and phosphate supplements. Once the serum potassium had risen to $3.0 \mathrm{mmol} / \mathrm{litre}$, sodium bicarbonate in a dose of $2 \mathrm{mmol} / \mathrm{kg} / \mathrm{d}$, was also given. His acidosis and hypokalaemia were corrected during the first three days in ICU. Ultrasonographic and radiological examination of the kidneys showed no abnormality, excluding medullary sponge kidney, nephrocalcinosis, and obstructive uropathy as potential causes of distal renal tubular acidosis.

While in ICU, further blood tests were arranged to establish the cause of his distal renal tubular acidosis. The results were as follows: total protein $57 \mathrm{~g} /$ litre (60-80), albumin $27 \mathrm{~g} /$ litre (35-50), IgA $5.48 \mathrm{~g} /$ litre $(0.8-4.0)$, IgG $12.7 \mathrm{~g} /$ litre (5.3-16.5), IgM $0.68 \mathrm{~g} /$ litre $(0.5-2.0)$. No paraprotein was found on serum electrophoresis. Urine was negative for BenceJones protein. Autoantibody profile showed negative anti-mitochondrial, anti-smooth muscle, anti-double stranded DNA, and antisalivary gland antibodies. However, testing for anti-nuclear antibody was positive (speckled pattern) and an extractable nuclear antigen (ENA) screen was positive owing to Ro/SSA antigen only. Rheumatoid factor was positive and complement components $\mathrm{C} 3$ and $\mathrm{C} 4$ were low at $0.55 \mathrm{~g} /$ litre $(0.7-1.7)$ and $0.13 \mathrm{~g} /$ litre $(0.14-0.44)$, respectively. This autoantibody pattern was consistent with Sjögren syndrome. There was no history of dry eyes and dry mouth; Schirmer test and salivary gland biopsy were not performed.

\section{Discussion}

Renal tubular acidosis is a syndrome of varied aetiology, with disordered renal acidification and potassium wastage resulting in hyperchloraemic hypokalaemic metabolic acidosis. Severe hypokalaemia may rarely lead to sudden life threatening paralysis and can reveal a previously undiagnosed disease process. In a patient presenting with severe hypokalaemia, evaluation of the acid-base status is helpful in narrowing the differential diagnosis. As our case showed, simple measurement of serum bicarbonate and chloride was enough to establish the diagnosis of hypokalaemic hyperchloraemic metabolic acidosis, and a random urinary $\mathrm{pH}$ of 6.5 while the patient was acidotic confirmed distal renal tubular acidosis as the underlying mechanism. The next step was to search for the cause of the distal renal tubular acidosis. Paraproteinaemia was excluded by normal serum protein electrophoresis and negative urinary Bence-Jones protein. A normal ultrasonographic and radiological examination of the kidneys excluded medullary sponge kidney, nephrocalcinosis, and obstructive uropathy as potential causes. Autoimmunity studies showed findings consistent with Sjögren syndrome despite the absence of the sicca symptoms, though distal renal tubular acidosis can precede the sicca syndrome by several months or even years. This case was unusual in that the patient was an elderly man-rather atypical for Sjögren syndrome which tends typically to affect middle aged women (the female to male ratio is 9:1). Therefore the finding of hypokalaemic paralysis caused by distal renal tubular acidosis in an elderly man should not discourage one from considering Sjögren syndrome as a possible cause.

The pathogenesis of distal renal tubular acidosis in Sjögren syndrome is an autoimmune tubulo-interstitial nephropathy. Glucocorticoid treatment has therefore been tried and has been shown to result in improvement. ${ }^{78}$ The emergency management of distal renal tubular acidosis with severe hypokalaemic muscle paralysis and acidosis consists of intravenous infusion of potassium followed by bicarbonate once the serum potassium is corrected to 3.0 $\mathrm{mmol} /$ litre, as illustrated in our case. After discharge from ICU, the patient was put on long term treatment with sodium bicarbonate orally in a dose of $1 \mathrm{mmol} / \mathrm{kg}$ daily. This is essential to prevent this catastrophic presentation from recurring. Given the severity of his distal renal tubular acidosis - a reflection of the severity of autoimmune interstitial nephropathy-it was felt appropriate to treat the patient with prednisolone in an initial dose of $1 \mathrm{mg} / \mathrm{kg} / \mathrm{d}$, tapered to $10 \mathrm{mg}$ daily. Serum urea and electrolytes are monitored regularly at follow up. Six months after the initial illness the patient remains well, with weight gain and improved exercise tolerance.

\section{CONCLUSIONS}

Autoimmune investigations for Sjögren syndrome should be instigated in any patient presenting with hypokalaemic paralysis from distal renal tubular acidosis, even in the absence of the sicca syndrome.

1 Siamopoulos KC, Elisaf M, Drosos AA, et al. Renal tubular acidosis in primary Sjögren's syndrome. Clin Rheumatol 1992;11:226-30.

2 Rowbottom SJ, Ray DC, Brown DT. Hypokalaemic paralysis associated with renal tubular acidosis. Crit Care Med 1987;15:1067-8.

3 Chang YC, Haung CC, Chiou CY. Renal tubular acidosis complicated with hypokalaemic periodic paralysis. Pediatr Neurol 1995;13:52-4.

4 Dowd JE, Lipsky PE. Sjögren's syndrome presenting as hypokalemic periodic paralysis. Arthritis Rheum 1993;36: $1735-8$

5 Zimhony O, Sthoeger Z, David DB, et al. Sjögren's syndrome presenting as hypokalemic paralysis due to distal renal tubular acidosis. F Rheumatol 1995;22:2366-8.

6 Christensen KS. Hypokalemic paralysis in Sjögren's syndrome secondary to renal tubular acidosis. Scand 7 Rheumatol 1985;14:58-60.

7 Crooks GW, Zweiman B. An unusual presentation of Sjögren's syndrome. Clin Diag Lab Immunol 1996;3:483-4.

8 El-Mallakh RS, Bryan RK, Masi AT, et al. Long term low-dose glucocorticoid therapy associated with remission
of overt renal tubular acidosis in Sjögren's syndrome. $A m \mathcal{F}$ Med 1985;79:509-14. 